\title{
O uso da tipografia nas interfaces de jogos: uma leitura multimodal
}

\section{The use of typography in gaming interfaces: a multimodal reading}

\author{
Cristiana Barbosa Nunes da Silva ${ }^{a}$; Vânia Soares Barbosa ${ }^{b}$ \\ a Instituto Federal de Educação, Ciência e Tecnologia do Piauí, Piauí, Brasil- cristiana@ifpi.edu.br \\ a Universidade Federal do Piauí, Piauí, Brasil - vaniasb@ufpi.edu.br
}

\section{Palavras-chave: Jogos. Tipografia. Multimodalidade. Leitura.}

Keywords: Games. Typography. Multimodality. Reading.
Resumo: Este artigo analisa o uso da tipografia presente nas interfaces de jogos digitais e promove uma análise multimodal com base na Gramática do Design Visual, de Kress e van Leeuwen (2006). Como suporte teórico para este estudo abordamos sobre multimodalidade (KRESS; VAN LEEUWEN, 2006), multiletramentos (THE NEW LONDON GROUP, 1996), jogos digitais (GEE, 2003) e tipografia (VAN LEEUWEN, 2006). Com o objetivo de analisar a contribuição da tipografia e da GDV nas interfaces de jogos digitais, investigamos quatro prints de jogos que contenham diálogos entre os participantes durante a jogabilidade. Os jogos selecionados foram Operate Now: Hospital (Spil Games, 2017), Gardenscapes (Playrix, 2016), Matchington Mansion (Firecraft Studios, 2017) e Hometown Romance (Pretty Teen Games, 2018). Com isso, pudemos observar através da tipografia e análise imagética a contribuição dos recursos semióticos e seu potencial comunicativo em jogos, proporcionando uma leitura multimodal e destaca seu poder comunicativo, atribuindo significados a diferentes modos, não apenas ao verbal.

Abstract: Technological advances and their consequences in social life have promoted new forms of access to reading, making possible new social practices. These practices are carried out through new means of communication, such as applications, social networks, games, among others. This article analyzes the use of typography present in the interfaces of digital games and promotes an analysis of the multimodal reading, based on Grammar of Visual Design, by Kress and van Leeuwen (2006). We approach multimodality (KRESS; VAN LEEUWEN, 2006), multiliteracies (THE NEW LONDON GROUP, 1996), digital games (GEE, 2003) and typography (VAN LEEUWEN, 2006) as theoretical support for this study. In order to analyze the contribution of typography and multimodality in the reading process of digital games, we investigated game screenshots that contain dialogues during the gameplay. We can observe through typography and imagery analysis the contribution of semiotic resources and their communicative potential in games, providing a multimodal reading, assigning meaning and communicative power to aspects that go beyond the verbal text. 


\section{Introdução}

Os avanços nas tecnologias de comunicação e informação têm proporcionado a inserção de diferentes ferramentas digitais que passam a fazer parte cada vez mais de nossa vida cotidiana, entre elas os computadores, tables e smartphones e, por meio dessas, as redes sociais, os aplicativos com as mais diferentes funções, os jogos, entre outras formas de interação. Lidar com essas tecnologias digitais exige novos conhecimentos, uma vez que as mudanças em suas interfaces e aplicabilidades são rápidas e constantes e, portanto, estar aptos a utiliza-las passa a ser uma condição para atuarmos na sociedade contemporânea que se mantêm interligada virtualmente.

Entre esses novos conhecimentos necessários para entendermos o impacto das tecnologias digitais de comunicação e informação (TDCI) na vida social e, particularmente, no ambiente educacional, destacamos a leitura que precisa ser repensada para que possa abranger outros modos semióticos, não apenas os códigos verbais, tais como sons e recursos visuais, entre eles as imagens (estáticas e em movimento), cores, layout, e a tipografia. A estes recursos são atribuídos significados e funções que ultrapassam a noção de adornos decorativos e, portanto, precisam ser integrados no ato de leitura que, por sua vez, passa a ser uma leitura multimodal.

Esta integração é possível por meio de uma inter-relação entre as diversas formas de significar, tais como o texto verbal escrito, a tipografia empregada, as imagens, som, entre outras formas, sendo que cada forma apresenta um significado de acordo com a sua limitação (KRESS; VAN LEEUWEN, 2006). A esta integração dá-se o nome de multimodalidade, uma abordagem que considera a produção de significado por meio da relação entre os vários modos semióticos (VAN LEEUWEN, 2011).

Em relação às TDCI, os jogos digitais são exemplos dessas tecnologias e estes apresentam o uso de vários modos semióticos em suas composições, portanto, constituem-se em um ambiente multimodal com um rico potencial para exploração. Esta diversidade de modos instigou-nos a verificar como estes recursos, em especial a tipografia, e as funções dos modos semióticos apresentadas pela Gramática do Design Visual (GDV), de Kress e van Leeuwen (2006), contribuem para uma leitura multimodal nas interfaces dos jogos. 
Assim, este artigo busca mostrar meios nos quais a tecnologia, em especial os jogos digitais, podem promover a interação e o acesso a novos modos de leitura, através da tipografia e das informações visuais integradas de vários modos.

Como objeto de análise selecionamos quatro jogos que apresentam características para esta investigação, são eles: Operate Now: Hospital ${ }^{1}$ (Spil Games, 2017), Gardenscapes² (Playrix,2016), Matchington Mansion ${ }^{3}$ (Firecraft Studios, 2017) e Home Town Romance $^{4}$ (Pretty Teen Games, 2018), dos quais capturamos e analisamos quatro prints. Por conta dos direitos autorais, disponibilizamos o link para acesso aos jogos analisados nesta investigação.

As principais ideias teóricas que dão suporte às análises são apresentadas a seguir, iniciando com a discussão sobre a tecnologia e sua contribuição para o ensino, com destaque para os jogos digitais, uma ferramenta que vem sendo utilizada no meio educativo devido ao seu aspecto lúdico bem como seu potencial de recursos semióticos multimodais, entre eles a tipografia, que exploramos nesta investigação.

\section{Tecnologia, jogos digitais e ensino}

É comum encontrarmos notícias sobre as consequências dos avanços tecnológicos, tais como a quantidade de jovens atualmente conectados, a facilidade de acesso às ferramentas tecnológicas, entre elas os jogos digitais, smartphones, entre outros. Isto tem destacado a importância em lidar com novas possibilidades de interação promovidas por meio de tais ferramentas. Como consequência, os usuários destes recursos tecnológicos podem enfrentar desafios para acompanhar esta evolução, uma vez que as tecnologias têm o poder de atrair ou afastá-los, dependendo se são vistos como benéficos ou não.

Ao abordarmos sobre tecnologia, é comum associá-la com a tecnologia digital vigente. Porém é interessante verificarmos como era o acesso à tecnologia no início dos tempos. Voltando para o período do surgimento humano e suas primeiras manifestações de uso

\footnotetext{
${ }^{1} \mathrm{https}$ //spilgames.com/operate-now-hospital-game-begins/

2 https://www.playrix.com/gardenscapes/

${ }^{3}$ http://www.firecraftstudios.com/

${ }^{4}$ https://play.google.com/store/apps/details?id=com.prettyteengames.love.story.games.home.romance \&hl $=\mathrm{en}$
} 
tecnológico, de acordo com Veraszto et all (2008), já havia indícios de usos tecnológicos como a criação de ferramentas usadas para a caça e a pesca e vestígios de prática agrícola.

Desta forma, é possível percebermos que sempre houve uma ligação entre tecnologia e a capacidade humana de planejar, produzir e executar, baseada na necessidade humana que inicialmente era de subsistência e proteção, mesmo sem ainda ter sido desenvolvido um conhecimento científico, até chegar nos campos da saúde, educação, segurança, entre outros. A tecnologia tem proporcionado criações e adaptações de tecnologias existentes. Como exemplo citamos os jogos digitais, que são ferramentas tecnológicas em sua maioria desenvolvida para o entretenimento e que vem sendo utilizada no ambiente educacional.

Alguns estudos sobre o uso eficiente de jogos em sala de aula destacam o potencial que esta ferramenta tem em contribuir com o processo de ensino/aprendizagem. Gee (2003) tem desenvolvido pesquisas sobre a importância dos jogos e o que eles podem ensinar, seja na escola, trabalho, família e para pesquisadores acadêmicos. Ele destaca seu caráter desafiador, mas executável e motivador. Entre as qualidades citadas, destaca a possibilidade do jogador em se tornar produtor e não apenas consumidor, o que possibilita ao usuário ser ativo na construção do conhecimento. Outra habilidade que Gee (2003) destaca é a motivação, considerada a mais importante por ele e credita a ela os resultados da boa interação entre jogador e jogos.

Além desses aspectos, destacamos a riqueza multimodal presente nas interfaces dos jogos digitais. Estas, em sua maioria, são constituídas de uma variedade de recursos semióticos, tais como os já mencionados no início desse artigo, que além de atrair seus usuários pelo seu valor estético, também os desafia a integrar aqueles recursos a fim de que possam eficientemente entender a mensagem de seus produtores e, quando isso acontece, os jogos podem ser entendidos, então, como eventos comunicativos. Para entender esse processo, recorremos à multimodalidade e, com base nessa, a Gramática do Design Visual (KRESS; VAN LEEUWEN, 2006).

\section{Multimodalidade}


O caráter múltiplo da comunicação nos permite expor nosso posicionamento sobre algo de formas variadas. Mesmo quando utilizamos a linguagem verbal, seja na escrita, com o uso de tipografia (fonte, tamanho, estilo), por exemplo, ou na fala, como o tom e intensidade da voz, encontramos a presença de recursos multimodais variados, reforçando o uso desta abordagem na comunicação de uma forma geral.

Nesse sentido, a Multimodalidade refere-se ao uso integrado de diferentes modos e recurso semióticos na comunicação, tais como o verbal, gestual, sonoro, entre outros (VAN LEEUWEN, 2001), ou seja, mais de um modo semiótico em eventos de representação e/ou comunicação. No contexto educacional, Kress e van Leeuwen (2006) foram os pioneiros nos estudos desta abordagem que tem ganhado mais destaque especialmente a partir do final do século XX com o lançamento da Gramática do Design Visual (GDV), elaborada pelos autores com base na Gramática Sistêmico Funcional (GSF), de Halliday (1985).

A GDV é uma gramática descritiva, considerada pelos próprios autores como um "recurso para começar a penetrar na compreensão do visual como representação e comunicação - de uma forma semiótica - e como um recurso no desenvolvimento de teorias e "gramáticas" da comunicação visual"5 (KRESS E VAN LEEUWEN, 2006, n.p). Fernandes e Almeida (2008, p.2) consideram que neste material seus autores "realizam uma paridade entre a gramática da língua e uma gramática visual”. De acordo com a GSF, a língua cumpre três metafunções - ideacional, interpessoal e textual. Kress e van Leeuwen (2006) se apropriam dessa ideia e afirmam que, assim como na linguagem verbal, as imagens e outros modos semióticos também o fazem. À essas metafunções, os autores chamam de significados representacionais, interativos e composicionais.

De acordo com Kress e van Leeuwen (2006), nesses significados os produtores do signo levam em consideração os aspectos cultural, social e psicológico de acordo com o contexto no qual estes estejam inseridos, sendo que os significados representacionais apresentam as intenções comunicativas do texto, destacando o que está sendo mostrado e seus participantes; nos interacionais, o foco é no que está representado e a relação com

\footnotetext{
5 "resource for beginning to make inroads into understanding the visual as representation and communication - in a semiotic fashion - and also as a resource in the development of theories and 'grammars' of visual communication". (Kress e van Leeuwen, 2006, n.p)
} 
o leitor e demais participantes; já os significados composicionais dizem respeito a como os modos se organizam no texto.

Neste artigo, nosso foco é a metafunção ideacional/significados interativos cujas categorias são apresentadas no Quadro 1:

Quadro 1 - Categorias da metafunção interativa com base na GDV

\begin{tabular}{|c|c|}
\hline Categoria & Característica \\
\hline $\begin{array}{l}\text { Contato: que } \\
\text { analisa o olhar do } \\
\text { participante } \\
\text { representado }\end{array}$ & $\begin{array}{l}\text { Demanda: quando o participante representado olha diretamente para o leitor } \\
\text { Oferta: quando o participante não dirige seu olhar para o leitor }\end{array}$ \\
\hline $\begin{array}{l}\text { Enquadramento: } \\
\text { analisa a imagem } \\
\text { de acordo com o } \\
\text { ângulo desta. }\end{array}$ & $\begin{array}{l}\text { Fechado: quando o ângulo da imagem é fechado, disponibilizando pouca } \\
\text { informação sobre o participante representado } \\
\text { Médio: quando apresenta um ângulo um pouco mais aberto, porém ainda não } \\
\text { contempla muita informação } \\
\text { Aberto: que apresenta o participante representado mais afastado do leitor, porém } \\
\text { com disponibilização de mais informação }\end{array}$ \\
\hline $\begin{array}{l}\text { Perspectiva: atribui } \\
\text { ideias do } \\
\text { participante } \\
\text { representado de } \\
\text { acordo com o } \\
\text { ângulo. }\end{array}$ & $\begin{array}{l}\text { Horizontal frontal: revela o que tem a ser visto; empatia } \\
\text { Horizontal oblíqua: não revela tudo; maior distanciamento e menor empatia. } \\
\text { Vertical elevado: atribui poder ao participante representado. } \\
\text { Vertical baixo: atribui poder ao leitor em relação ao participante. } \\
\text { Vertical nível do olhar: igualdade social com o participante. }\end{array}$ \\
\hline $\begin{array}{l}\text { Modalidade: } \\
\text { aproximação ou } \\
\text { distanciamento do } \\
\text { real. }\end{array}$ & $\begin{array}{l}\text { Naturalística alta: aproximação do real } \\
\text { Abstrata: apresenta apenas o necessário para representar uma imagem. } \\
\text { Sensorial: enfatiza os efeitos de prazer ou desprazer que a imagem pode causar } \\
\text { ao leitor. } \\
\text { Tecnológica: ênfase no uso prático da imagem, instruir, explicar, detalhar. }\end{array}$ \\
\hline
\end{tabular}

Fonte: adaptado da GDV (KRESS; VAN LEEUWEN, 2006).

Nesta investigação analisamos os prints dos jogos selecionados com bases na metafunção interativa. Os jogos digitais são exemplos de ferramenta tecnológica com recursos semióticos multimodais tais como o texto verbal, som, imagem, movimento. Com essa evolução tecnológica veio a necessidade da habilidade de lidar com estes e outros novos recursos inseridos também no meio educacional. Sobre esta inserção abordamos a seguir no tópico multiletramentos. 


\section{Multiletramento}

Em meio às várias ferramentas tecnológicas atuais e suas constantes atualizações, o usuário muitas vezes encontra-se em busca de conhecimentos para acompanhar tais evoluções. Esta é uma das razões pelas quais surgiram os multiletramentos. Um grupo de dez estudiosos se reuniram em 1994, destacando a necessidade de adaptação das formas educacionais aos diversos modos semióticos multimodais existentes que pudessem contribuir para o ensino/aprendizagem, bem como novas formas comunicativas, cultuais e linguísticas. Este grupo intitulou-se The New London Group. Entre os multiletramentos destacamos para este estudo o letramento visual.

\subsection{Letramento Visual}

A imagem se faz presente na nossa rotina como ferramenta de comunicação desde o início dos tempos. Os primeiros registros de comunicação humana aconteceram através de recursos visuais. Santaella e Noth (1997, p.3) enfatizam isto ao afirmar que "as imagens têm sido expressões da cultura humana desde as pinturas pré-históricas das cavernas, milênios antes do aparecimento da palavra pela escritura". Com o surgimento da escrita, a imagem passou a ser utilizada mais como adorno que detentora de significado, mas volta a ser vista como meio comunicativo devido à evolução tecnológica das últimas décadas.

Atualmente, para poder lidar com a imagem, ler sua apresentação, compreender a intenção do autor ao cria-la e fazer sua própria interpretação frente às diversas possibilidades de formas imagéticas que existem é necessário um conhecimento para poder depreender significados e usá-la como meio de comunicação. Surge, então, a necessidade de um letramento visual que é definido por Barbosa (2017, p. 101) como "a capacidade de ler, entender, interpretar e utilizar informações visuais em eventos comunicativos, o que também inclui integrar texto e imagem nesses eventos".

Serafini (2014) ao definir o letramento visual julga importante considerar os aspectos social e cognitivo como parte deste letramento, enfatizando o processo de interpretação contínuo e a utilização de modos variados, destacando ainda a importância em considerar o contexto no qual a imagem é produzida e disseminada. 


\section{Tipografia}

A multimodalidade está presente em todos os tipos de comunicação, envolvendo mais de um recurso semiótico. Observar a forma visual da escrita é um modo de perceber a importância das diversas maneiras de significar através de usos alternados de tipografia. O uso frequente deste recurso em diversas áreas como jornais, outdoors, propagandas, livros, sites, entre outros é um exemplo do reconhecimento do seu poder semiótico, uma vez que está presente em diversas formas de comunicação.

Van Leeuwen (2006) comenta que a tipografia antes da evolução tecnológica atual não era considerada como um modo semiótico, sendo utilizado apenas como um adorno da escrita. Atualmente, de acordo com este autor, a tipografia vem ganhando novos espaços e destaque. Com o advento da tecnologia, mudanças na forma de representar e associar significados estão acontecendo. Van Leeuwen (2006) comenta a transformação que tem ocorrido na escrita uma vez que alterou a forma daquela ser realizada, passando a utilizar outros meios para significar como a tipografia, cor e layout. Surgiu então uma tipografia com uso de meios gráficos e inovações que possibilitaram novas formas de criar e transformar a comunicação visual, surgindo assim, uma nova escrita. Esta nova tipografia agora é disponibilizada principalmente por meio tecnológico digital e que possibilita ao leitor tornar-se designer e, segundo Van Leeuwen (2006), participar ativamente na criação e edição destas formas.

O autor supracitado destaca que não se trata de uma imposição e, sim, de propostas para semiotizar a tipografia, o que não era considerado em estudos anteriores. Ele fez observações sobre as características peso, expansão, inclinação, curvatura, conectividade, orientação e regularidade. Apresentamos no quadro 2 as categorias e algumas características tipográficas com base em Van Leeuwen (2006).

Quadro 1 - Categorias tipográficas

\begin{tabular}{l|l}
\hline Categoria & Característica \\
\hline Peso & $\begin{array}{l}\text { ousadia, assertivo, ou sólido e substancial, por exemplo, e seu oposto pode significar } \\
\text { tímido ou insubstancial. }\end{array}$ \\
\hline Expansão & condensadas, estreitas, ou expandida, larga. \\
\hline
\end{tabular}




\begin{tabular}{l|l}
\hline Inclinação & $\begin{array}{l}\text { um contraste entre o orgânico e o mecânico, o pessoal e o impessoal, o formal e o } \\
\text { informal, o produzido em massa e o artesanal, o novo e o velho, e assim por diante. }\end{array}$ \\
\hline Curvatura & $\begin{array}{l}\text { Sem angularidade: suave, macio, natural, orgânico, maternal; com presença de } \\
\text { ângulos: abrasivo, duro, técnico, masculino, entre outras. }\end{array}$ \\
\hline Conectividade & $\begin{array}{l}\text { desconexão externa: atomização ou fragmentação; conexão externa: totalidade ou } \\
\text { integração; internamente desconectadas: abotoadas, inacabadas, desleixadas ou fáceis. }\end{array}$ \\
\hline Orientação & $\begin{array}{l}\text { horizontal: peso, solidez, inércia, autossatisfação; vertical: leveza, aspiração } \\
\text { ascendente, instabilidade. }\end{array}$ \\
\hline Regularidade & irregularidades de tamanho, espessura, formato, entre outras. \\
\hline
\end{tabular}

Fonte: própria com base em Van Leeuwen (2006).

\section{Considerações metodológicas}

\subsection{Descrição do material investigado}

Esta é uma investigação qualitativa e descritiva de cunho bibliográfico. Iniciamos esta investigação com a seleção dos jogos para a análise dos prints. O critério para a escolha destes era conter diálogos durante a jogabilidade. As categorias utilizadas para a análise foram as categorizações tipográficas propostas por van Leeuwen (2006) bem como as características multimodais de acordo com a metafunção interativa da GDV (KRESS; VAN LEEUWEN, 2006). Selecionamos quatro jogos e destes escolhemos um print de cada jogo que continha as características adequadas para esta pesquisa. Os jogos selecionados foram: Operate Now: Hospital (Spil Games, 2017), Gardenscapes (Playrix, 2016), Matchington Mansion (Firecraft Studios, 2017) e Hometown Romance (Pretty Teen Games, 2018). Na sequência, procedemos com a análise destes prints, apresentados no tópico a seguir.

\section{Procedimentos de análises e discussão dos resultados}

Começamos esta seção com a análise do print 1 relacionado ao jogo Operate now: Hospital (Spil Games, 2017). Este jogo é ambientado em um hospital e possibilita ao jogador gerenciar as atividades deste, bem como realizar tarefas, atuando em áreas como médico, enfermeiro, recepcionista, entre outros. O print 1 apresenta a imagem do tórax de uma pessoa em uma sala de cirurgia, focalizando o abdômen onde será 
realizado o procedimento. Nas laterais direita e esquerda da imagem o jogador tem acesso aos instrumentos cirúrgicos e na parte inferior há uma caixa de diálogo com a foto da médica e a frase: "Bom! Agora estamos prontos para fazer a incisão. Selecione a ferramenta BISTURI.”

O print número 2 pertence ao jogo Gardenscapes (Playrix, 2016). O ambiente onde o jogo acontece é um jardim que possibilita ao jogador decorá-lo, podendo trocar móveis, plantas, reformar espaços, entre outras atividades. Este print em análise apresenta o mordomo Austin, a direita, ao telefone, em meio ao jardim, próximo a uma casa na árvore. No canto superior esquerdo é disponibilizado a tarefa a ser realizada. A mensagem sugere a derrubada da casa na árvore. No lado direito da imagem aparece Roberto, o funcionário responsável pelas reformas e que fala ao telefone com Austin. Na parte inferior do print aparece novamente a imagem de Austin e a frase: "É claro que te ajudo. Mas primeiro precisamos derrubar a casa antiga para começarmos a construir uma nova!"

O print número 3 está relacionada ao jogo Matchington (Firecraft Studios, 2017). O jogo acontece em uma casa velha, herdada pela personagem principal, Tiffany, que tenta, juntamente com o jogador torná-la habitável, através, principalmente, de troca de mobília. A imagem capturada apresenta a sala de estar da mansão, com aspecto de desgaste e descuido e sua nova dona, Tiffany, próxima às escadas que dão acesso ao andar superior. Na parte inferior da imagem, aparece um balão direcionado a outra imagem da Tiffany, em tamanho maior, com a frase: "Ótimo! Vamos pegar aquela mesinha de centro nova!"

O print 4 refere-se ao jogo Hometown Romance (Pretty Teen Games, 2018). Este jogo possibilita o jogador vivenciar a rotina de uma família na qual uma das filhas retorna à cidade para ajudar a cuidar de seu pai que está doente e ela tenta dar apoio à mãe e à irmã por conta desta situação. A imagem capturada apresenta a personagem Cris, na sala de sua casa, em pé, direcionada diretamente para o jogador. Na parte inferior da tela aparece um balão, direcionado à Cris, com a frase: "Você não pode ser descuidado com sua saúde enquanto cuida dele, ok? EU ESTOU AQUI AGORA”. 
Uma vez ambientados das cenas selecionadas para esta investigação por meio de suas descrições, apresentamos no quadro 3 as características tipográficas presentes nos jogos analisados, seguindo a categorização proposta por van Leeuwen (2006):

Quadro 2 - Características tipográficas dos jogos analisados

\begin{tabular}{|c|c|c|c|c|}
\hline \multirow[b]{2}{*}{ Categorias } & \multicolumn{4}{|c|}{ Características } \\
\hline & $\begin{array}{c}\text { Características } \\
\text { representadas no } \\
\text { jogo Operate now: } \\
\text { Hospital }\end{array}$ & $\begin{array}{c}\text { Características } \\
\text { representadas no } \\
\text { jogo } \\
\text { Gardenscapes }\end{array}$ & $\begin{array}{c}\text { Características } \\
\text { representadas no } \\
\text { jogo Matchington }\end{array}$ & $\begin{array}{c}\text { Características } \\
\text { representadas no } \\
\text { jogo Hometown } \\
\text { Romance }\end{array}$ \\
\hline Peso & $\begin{array}{c}\text { Ausência; sugere } \\
\text { timidez, sem } \\
\text { destaque }\end{array}$ & $\begin{array}{l}\text { Ausência; sugere } \\
\text { timidez, sem } \\
\text { destaque }\end{array}$ & $\begin{array}{c}\text { Ausência; sugere } \\
\text { timidez, sem } \\
\text { destaque }\end{array}$ & $\begin{array}{c}\text { Ausência; sugere } \\
\text { timidez, sem } \\
\text { destaque }\end{array}$ \\
\hline Inclinação & $\begin{array}{l}\text { Ausência; sugere } \\
\text { formalidade }\end{array}$ & $\begin{array}{l}\text { Ausência; sugere } \\
\text { formalidade }\end{array}$ & $\begin{array}{l}\text { Ausência; sugere } \\
\text { formalidade }\end{array}$ & $\begin{array}{l}\text { Ausência; sugere } \\
\text { formalidade }\end{array}$ \\
\hline Conexão & $\begin{array}{l}\text { Ausência; sugere } \\
\text { Individualidade }\end{array}$ & $\begin{array}{l}\text { Ausência; sugere } \\
\text { Individualidade }\end{array}$ & $\begin{array}{l}\text { Ausência; sugere } \\
\text { Individualidade }\end{array}$ & $\begin{array}{l}\text { Ausência; sugere } \\
\text { Individualidade }\end{array}$ \\
\hline Curvatura & $\begin{array}{c}\text { Presença; sugere } \\
\text { naturalidade, } \\
\text { leveza }\end{array}$ & $\begin{array}{l}\text { Presença; sugere } \\
\text { naturalidade, } \\
\text { orgânico }\end{array}$ & $\begin{array}{c}\text { Presença; sugere } \\
\text { naturalidade, } \\
\text { leveza }\end{array}$ & $\begin{array}{l}\text { Presença; sugere } \\
\text { aspecto maternal, } \\
\text { suave }\end{array}$ \\
\hline Orientação & $\begin{array}{l}\text { Vertical; leveza e } \\
\text { instabilidade }\end{array}$ & $\begin{array}{c}\text { Vertical; leveza e } \\
\text { instabilidade }\end{array}$ & $\begin{array}{l}\text { Vertical; leveza e } \\
\text { instabilidade }\end{array}$ & $\begin{array}{l}\text { Vertical; leveza e } \\
\text { instabilidade }\end{array}$ \\
\hline Expansão & Ausência; precisão & Ausência; precisão & $\begin{array}{l}\text { Ausência; } \\
\text { precisão, } \\
\text { economia }\end{array}$ & $\begin{array}{c}\text { Ausência; precisão, } \\
\text { economia }\end{array}$ \\
\hline Regularidade & $\begin{array}{c}\text { Presença; segue } \\
\text { regras }\end{array}$ & $\begin{array}{c}\text { Presença; segue } \\
\text { regras }\end{array}$ & $\begin{array}{c}\text { Presença; segue } \\
\text { regras }\end{array}$ & $\begin{array}{c}\text { Presença; segue } \\
\text { regras }\end{array}$ \\
\hline
\end{tabular}

Fonte: própria adaptado de van Leeuwen (2006).

Com base nestas informações disponibilizadas, observamos que na tipografia empregada nos quatro jogos analisados, foram recorrentes os seguintes aspectos: ausência do peso, significando uma discrição na informação disponibilizada; ausência de inclinação, sugerindo aspecto formal do conteúdo disponibilizado; ausência de conexão entre as letras, representando a individualidade das participações; presença de curvatura nas letras, indicando a forma natural de abordagem do conteúdo; orientação 
vertical representando a instabilidade, comum em jogos; ausência de expansão entre as letras, relacionado às decisões de jogadas precisas; e presença de regularidade, relacionado a capacidade dos personagens e jogador em seguir as regras propostas pelo jogo.

Sobre a GDV (KRESS; VAN LEEUWEN, 2006) analisamos as imagens de acordo com a metafunção interativa e suas categorias. Apresentamos na sequência as características encontradas nos jogos analisados:

Quadro 3 - Categorias analisadas segundo a GDV

\begin{tabular}{|c|c|c|c|c|}
\hline \multirow{2}{*}{$\begin{array}{l}\text { Categorias da } \\
\text { GDV }\end{array}$} & \multicolumn{4}{|c|}{ Jogo } \\
\hline & $\begin{array}{l}\text { Operate now: } \\
\text { Hospital }\end{array}$ & Gardenscapes & Matchington & $\begin{array}{c}\text { Hometown } \\
\text { Romance }\end{array}$ \\
\hline Contato & $\begin{array}{l}\text { olhar de } \\
\text { demanda }\end{array}$ & $\begin{array}{l}\text { olhar de oferta do } \\
\text { participante representado } \\
\text { Austin; olhar de demanda } \\
\text { do participante } \\
\text { representado Roberto. }\end{array}$ & $\begin{array}{l}\text { olhar de } \\
\text { demanda. }\end{array}$ & $\begin{array}{l}\text { olhar de } \\
\text { demanda. }\end{array}$ \\
\hline Enquadramento & plano fechado; & plano médio; & plano médio; & plano médio; \\
\hline Perspectiva & & $\begin{array}{l}\text { horizontal oblíqua; } \\
\text { vertical a nível do olhar; }\end{array}$ & $\begin{array}{c}\text { horizontal } \\
\text { ângulo frontal; } \\
\text { vertical } \\
\text { a nível do } \\
\text { olhar; }\end{array}$ & $\begin{array}{l}\text { horizontal } \\
\text { frontal; } \\
\text { vertical a nível } \\
\text { do olhar; }\end{array}$ \\
\hline Modalidade & $\begin{array}{c}\text { baixa } \\
\text { modalidade } \\
\text { naturalística; } \\
\text { alta } \\
\text { modalidade } \\
\text { abstrata. }\end{array}$ & $\begin{array}{c}\text { baixa modalidade } \\
\text { naturalística; } \\
\text { alta modalidade abstrata; }\end{array}$ & $\begin{array}{c}\text { baixa } \\
\text { modalidade } \\
\text { naturalística; } \\
\text { alta } \\
\text { modalidade } \\
\text { abstrata; }\end{array}$ & $\begin{array}{c}\text { baixa } \\
\text { modalidade } \\
\text { naturalística; } \\
\text { alta } \\
\text { modalidade } \\
\text { abstrata; }\end{array}$ \\
\hline
\end{tabular}

Fonte: própria adaptado da GDV (KRESS; VAN LEEUWEN, 2006)

Neste quadro percebemos a predominância do olhar de demanda, sugerindo um convite de interação do personagem para o leitor; plano médio na categoria enquadramento, significando uma tendência em apresentar informações limitadas e média aproximação do personagem com o leitor; perspectiva horizontal frontal, sugerindo uma interação 
direta com o leitor; perspectiva vertical a nível do olhar, indicando igualdade entre o personagem representado e o leitor; baixa modalidade naturalística e alta modalidade abstrata, características comum em jogos digitais por representarem objetos, pessoas e coisas.

\section{Considerações finais}

Após as análises feitas observamos a importância da tipografia como recursos semiótico multimodal e podemos perceber a sua contribuição para a caracterização dos personagens dos jogos, sugerindo informações implícitas sobre atitudes e personalidades dos participantes representados. Sobre a leitura multimodal, com base na GDV (KRESS; VAN LEEUWEN, 2006), observamos uma tendência em disponibilizar características que sugerem um contato direto com o leitor, convidando-o a interagir ao passo que o coloca na posição de um dos personagens e em situação de igualdade.

Desta forma, por meio das análises descritivas das imagens podemos observar a contribuição dos recursos semióticos presentes na tipografia destes jogos, proporcionando uma leitura multimodal, atribuindo significado e poder comunicativo aos aspectos que vão além do texto verbal, contribuindo para caracterizar e informar sobre o participante representado e a imagem em geral.

\section{REFERÊNCIAS}

BARBOSA, V. S. Multimodalidade e Letramento Visual: uma proposta de intervenção pedagógica para integrar as habilidades de ler e ver no processo de ensino e aprendizagem de inglês como língua estrangeira. Orientadora: Prof. a Dr. antônia Dilamar Araújo. 2017. 416 f. Tese (Doutorado em Linguística Aplicada) - Universidade Estadual do Ceará, Centro de Humanidades, Fortaleza, 2017. Disponível em: http://www.uece.br/posla/dmdocuments. Acesso em: 14 jun. 2019.

FERNANDES, J.D.C.; ALMEIDA, D.B.L. Revistando a Gramática Visual nos Cartazes de Guerra in: ALMEIDA, D.B.L(org.). Perspectiva em análise visual. João Pessoa: Editora da UFPB, 2008. 
GEE, J.P. What video games have to teach us about learning and literacy. New York: Palgrave/Macmillan, 2003.

HALLIDAY, M.A.K. An introduction to functional grammar. London: Edward Arnold, 1985.

JEWITT, C. Multimodality, reading and writing for the $21^{\text {st }}$ century. Discourse: Studies in the Cultural Politics of Education, University of London, v. 26, n. 3, p. 315-331, 2005 .

KRESS, G.; VAN LEEUWEN, T. Reading images: the grammar of visual design. London: Routledge, 2006

SANTAELLA, L; NOTH, W. Imagem: cognição, semiótica, mídia. São Paulo: Iluminuras, 1997.

SERAFINI, F. Reading the Visual: an introduction to teaching multimodal literacy. New York: Teacher College Press, 2014.

SERAFINI, F; CLAUSEN, J. Typography as semiotic resource. Journal of Visual Literacy, 2012, Volume 31, Number 2.

VAN LEEUWEN, T. Multimodality. In: SIMPSON, J. (org.). The Routledge Handbook of Applied Linguistics. London: Routledge, 2011. p. 668-682.

VAN LEEUWEN, T. Towards a semiotics of typography. Information Design Journal, v. 14, n. 2, 139-155, 2006.

VERASZTO, E.V; SILVA, D; MIRANDA, N.A; SIMON, F.O. Tecnologia: buscando uma definição para o conceito. Disponível em:

http://ojs.letras.up.pt/index.php/prismacom/article/viewFile/2078/1913. Acesso 22 nov. 2018.

\section{NOTAS DE AUTORIA}

Cristiana Barbosa Nunes da Silva (cristiana@ifpi.edu.br) é mestranda em Letras/Linguística pela Universidade Federal do Piauí (UFPI). Especialista em Metodologia do Ensino de Língua Inglesa (UNINTER).Graduada em Letras/Inglês (UFPI). Professora do Instituto Federal de Educação, Ciência e Tecnologia do Piauí (IFPI).Tem experiência na área de Letras, com ênfase em Língua Inglesa, atuando principalmente no seguinte tema: multimodalidade, multiletramentos e novas tecnologias.

Vânia Soares Barbosa (vaniasb@ufpi.edu.br) possui graduação em Ciências Econômicas pela Universidade Federal do Piauí (2000), graduação em Licenciatura Plena em Língua Estrangeira pela 
Universidade Federal do Piauí (2002), mestrado em Letras - Estudos Literários pela Universidade Federal do Piauí (2006) doutorado em Linguística Aplicada pelo Programa de Pós-Graduação em Linguística Aplicada da Universidade Estadual do Ceará (2017), com estágio de doutorado sanduíche (CAPES) na Universidade de Birmingham - Inglaterra. Atualmente é professora adjunto da Universidade Federal do Piauí, lotada na Coordenação de Letras Estrangeiras, membro do Colegiado e do Núcleo Estruturante daquela Coordenação e coordenadora pedagógica do Programa Idiomas sem Fronteiras - NucLi UFPI. Tem experiência na área de Letras, com ênfase em Línguas Estrangeiras Modernas, e interesse em ensino, tecnologia e formação de professores, com pesquisas que tratam de cinema e literatura (tradução intersemiótica e intertextualidade) e, mais recentemente, multimodalidade, multiletramentos, letramento visual e leitura de textos multimodais.

\section{Como citar este artigo de acordo com as normas da revista?}

SILVA, Cristiana Barbosa Nunes da; BARBOSA, Vânia Soares. O uso da tipografia nas interfaces de jogos: uma leitura multimodal. Texto Digital, Florianópolis, v. 16, n. 1, p. 266-280, 2020.

\section{Contribuição de autoria}

Cristiana Barbosa Nunes da Silva: realização da pesquisa, coleta e análise de dados e redação do artigo.

Vânia Soares Barbosa: revisão, construção do referencial teórico e das conclusões.

\section{Financiamento}

Não se aplica.

\section{Consentimento de uso de imagem}

Não se aplica.

\section{Aprovação de comitê de ética em pesquisa}

Não se aplica.

\section{Licença de uso}

Este artigo está licenciado sob a Licença Creative Commons CC-BY. Com essa licença você pode compartilhar, adaptar, criar para qualquer fim, desde que atribua a autoria da obra.

\section{Histórico}

Recebido em: 15/05/2020.

Aprovado em: 30/06/2020. 